\title{
Use of a Digital Information System to Achieve a Topographical Embossed Plan in Farcasesti Village, Gorj County
}

\author{
Luminița Livia BÂRLIBA ${ }^{1 *}$, Costel BÂRLIBA ${ }^{1}$ and Gabriel ELEȘ ${ }^{2}$ \\ ${ }^{1}$ Department of Rural Devevelopment and Environmental Engineering, Banat University of \\ Agricultural Sciences and Veterinary Medicine "King Mihai I" Timisoara, Romania \\ 2 Politehnica University Timisoara, Romania \\ *)Corresponding author, e-mail: liviabarliba@yahoo.com
}

BulletinUASVM Horticulture 73(2) / 2016

Print ISSN 1843-5254, Electronic ISSN 1843-5394

DOI:10.15835/buasvmcn-hort:12275

\begin{abstract}
The purpose of this paper is to obtain thematic maps and topographic analyses determined on the field and processed through the basic programs of AutoCAD, TopoLT and Global Mapper which along with topogeodezical details high up in on the field to create a database required to implement a feasibility study, as a previous step of the general cadastre in the Farcasesti village, Gorj county.

Topographical surveying were made with GNSS technology using the RTK-Kinematic method, South V-82 type in Real Time and data processing was performed by specialized graphics programs.

Field data collected with GPS RTK were transferred to a computer using specialized software LeicaGeo Combined Office and other software like Notepad, Excel, Word, AutoCAD 2013. The imported data from the field in three spatial coordinates, respectively $\mathrm{X}, \mathrm{Y}$ and Z, were the basis for drawing up planimetric situation plans by outlining the details of the terrain and elevation.

In the present paper, we demonstrate that the use of GPS technology made possible topogeodezical data collection from a large area with high precision in a short time using reduced material and human resources. This allowed us to import data from the field by using topogeodezical specialized programs and accurately achieve the outlines of buildings and perimeter, as verified by superimposing them on orthophotomap. Achieving digital plans using AutoCAD Architectural demonstrated that they can be made with accuracy and precision permitting various analyzes of land, including the construction of contour in 2D and 3D.
\end{abstract}

Keywords: Computing environment, Contour, GPS, Topographic plan.

\section{INTRODUCTION}

Any digital representation (numeric) of the landform continues variation in space is called (Popescu, 2009), digital elevation model (DEM) or digital terrain model (DTM). Other Z sizes may be shaped in elevation with the methods applied to altitude, such as pressure, temperature, acidity of the soil, land pollution, etc. In this case the study generally represents any themed variable values $\mathrm{Z}$ on a continuous area.
When DEM is created, considering only the accuracy degree, we must define the mass points distribution and the condition regarding the characteristic lines.

The mass points are generally disposed into a regular shape (grid with equal and uniform distance on North-South and East-West directions). Primary or basic data must be in the form of a network irregular triangles (TIN-Triangulated Irregular Network). (Herbei and Nemes, 2012). 


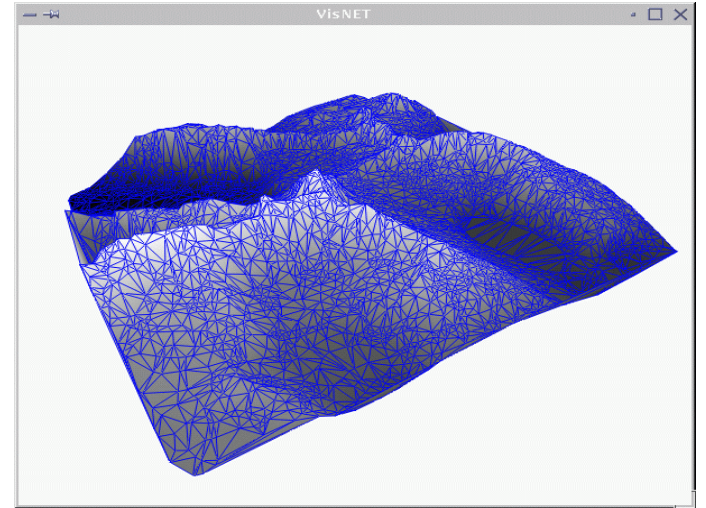

Fig.1. Mass points distribution

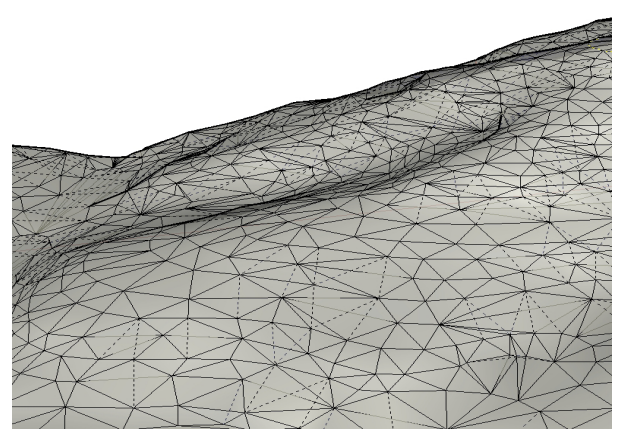

Fig.2. The grid mesh

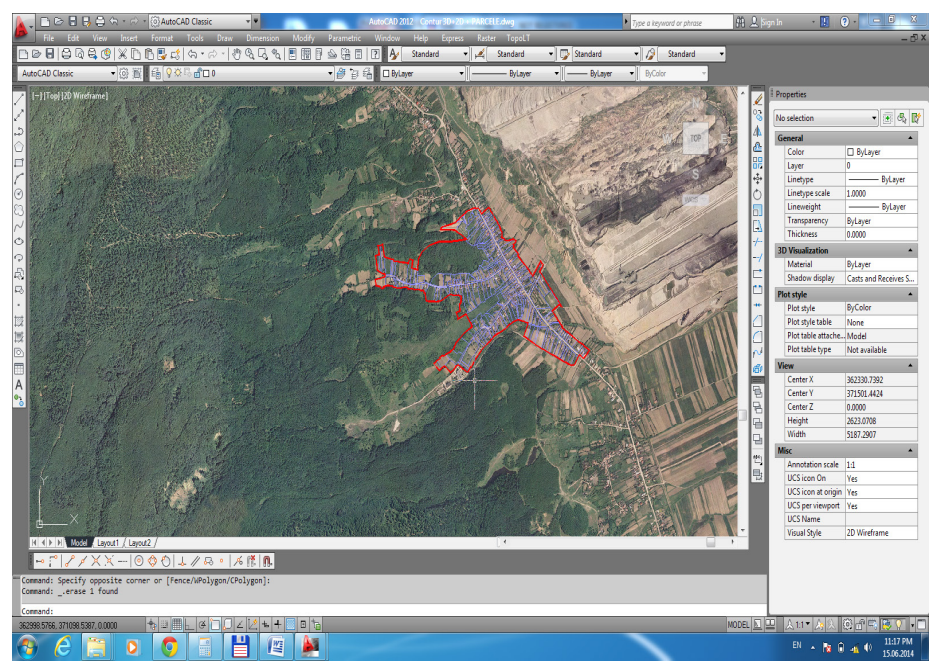

Fig. 3. Orthophotoplan image

Another important step used for the presentation is to specify the distance between the grid points. The grid mesh (fig.2) (Barliba and Stoian, 2009) must be sufficiently abundant to distinguish the natural shape of the terrain. The grid space must be defined as all kind of terrains (plain, hill and mountain).

Different accuracies on heights required different spatial grids. A higher density of the grid points leads to a very dense grid which will required high problems in joining lots of data.

\section{MATERIALS AND METHODS}

The area of interest for setting the parcel is situated in the urban South part of Fărcășesti village (fig.3).

Considering the altitude, the expansion varies between $148 \mathrm{~m}$. level curve and $198 \mathrm{~m}$. level curve (height references system Black Sea). This aspect requires creating a situation plan for the level curves, but for the correctitude of the work, it has been demanded for a contour situation plan to establish the total surface of the existent terrain.

The cadastral plane was made at 1:1000 scale, considering the topographical fields works, in the same time a lot of transversal profiles were achieved to determine the terrain relief.

The basic plans which were the backbone of the identification works considering from the topographical point of view, are aero photographical plans at 1:5000 scale, plans and topographical maps provided from the O.C.P.I. Gorj (fig.4) as well as actual orthophotoplans virtual edited during the years when the works were realized.

The following sections of maps and plans were used:

L - 34 - 119 - D - a - 1 - I - 1 - 1:2.000 scale

L - 34-119- D - a - 1 - I - $2 \quad$ - 1:2.000 scale

L - 34 - 119 - B - c - 3 - III - 4 - 1:2.000 scale 

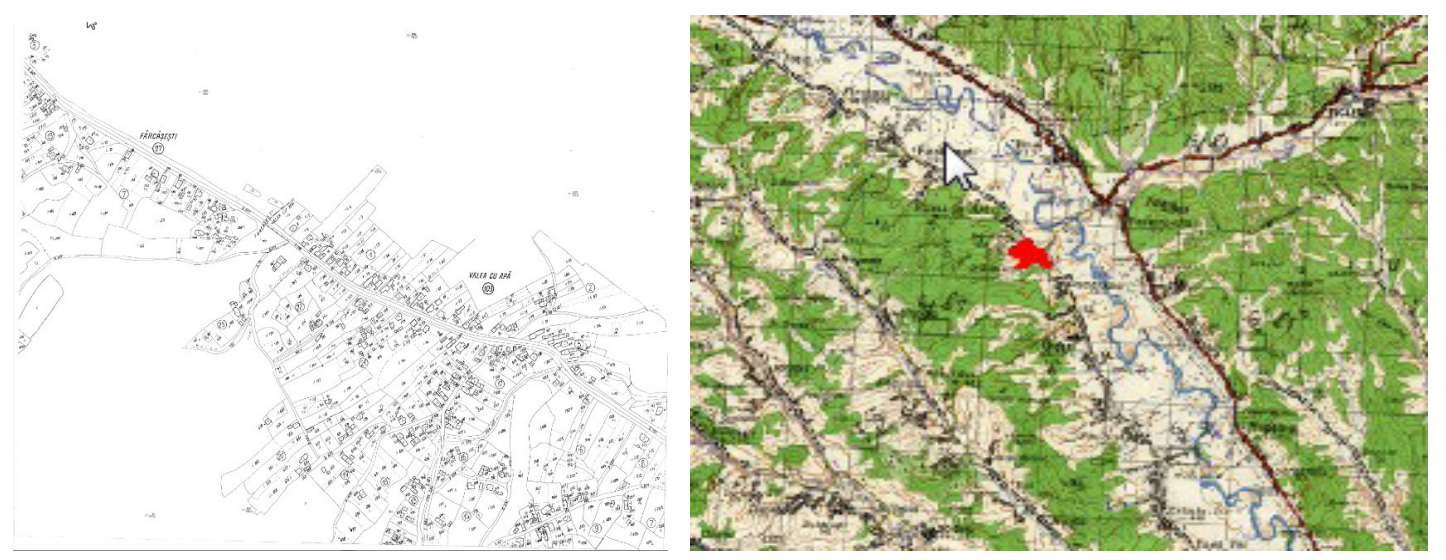

Fig. 4. Cadastral plan 1:2000 scale and Romania's map at 1:50.000 scale

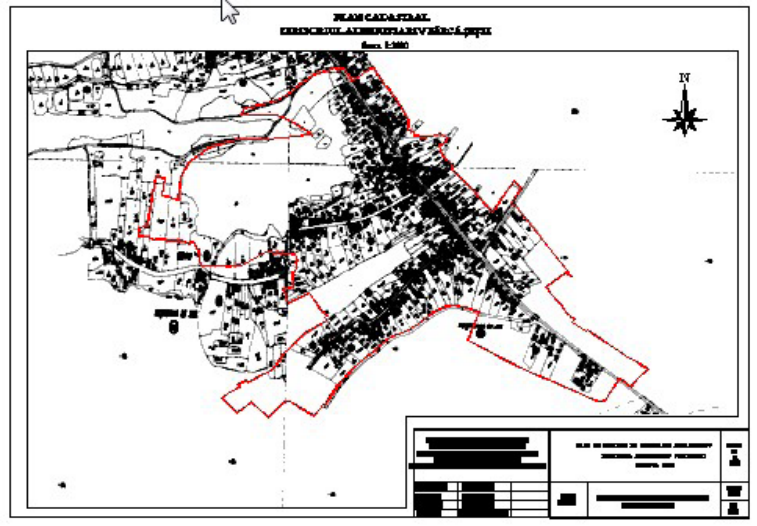

Fig.5. Framing plan in urban area at 1:2000 scale

\section{L - 34 - 119 - B - c - 3 - III - 3 - 1:2.000 scale}

The topographical map of Romania at 1:50 000 scale.

As part of the work, an area recognition was made in order to consider the existence of the geodetically points from the State Geodetic Network and the existent network on the plans and topographical maps and also in the knowing points coordinates catalogues as well as the coordinates known from previous topographical works found at O.C.P.I. GORJ.

The technical equipment used for the topographical works comprised of: 4 GPS receptors SOUTH S82-V with field book Unistrong ODION and for the signal amplifier an antenna amplifier was used.

\section{RESULTS AND DISCUSSION}

Mainly, most of topographical works were achieved by using the GNSS technology using

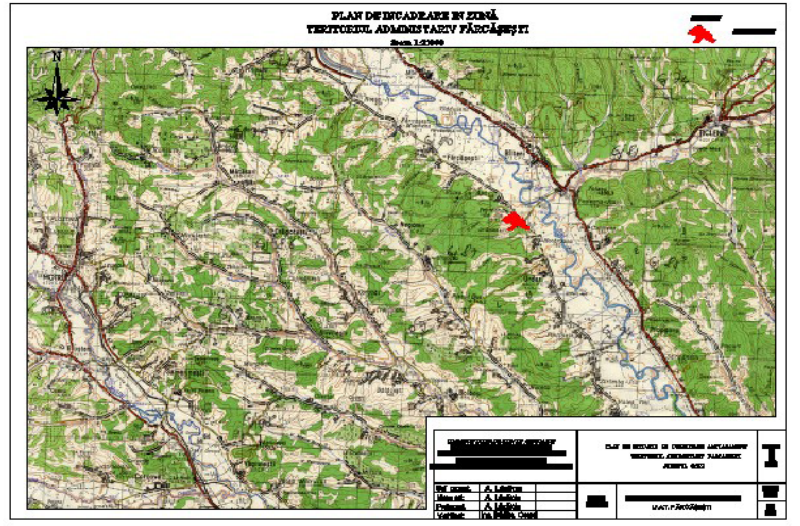

Fig.6. Framing plan at $1: 25000$ scale

RTK-Kinematic in Real Time, by using differential corrections in real time from an integrated station from the thickening network.

The working procedure consists in setting the base on a point of known coordinates from the geodetically thickening network, and connecting later the Rovers at the base by using the radio waves. For covering a vast area with the base signal, the base signal was retransmitted using an amplifier set on a tripod with a stronger antenna.

For verifying the measurements accuracy, every time, when the base was set, the coordinates of a point from the thickening network were determined by each receiver. The points were the base was set, were chosen in such a manner that they were covered with signal in the whole working territory especially in urban and locality radius.

In urban areas, considering the heights regime of buildings, each GPS operator was equipped with $5 \mathrm{~m}$ aluminium flexible stuff. Thus, the contour 


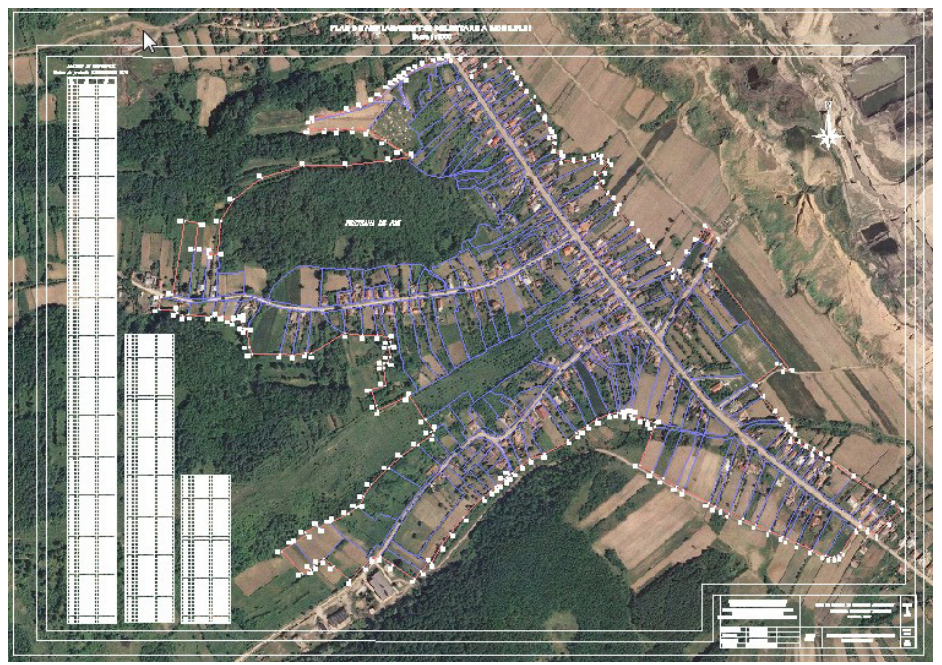

Fig. 7. Zonal plan on orthophotoplan, at 1:1000 scale

points of all proprieties and blocks were easily determined.

In the areas from outside the village, the working radius was larger because the signal covering degree was better. In these areas, teams of 2 operators were created, both deployed parallel along the channel banks or along the water courses for a better timing, coordination and efficiency increasing in this way the field measurements efficiency.

Points were measured, mainly along the linear details with permanent characteristics from the field, such as channels, water ways, roads, dams etc.

For the terrain with abundant vegetation or the terrain with high slopes the extensible stuffs were used, this leading us to measure coordinates for points situated in heavy areas.

The measured points from the present paper were processed through two methods: by using the Leica Geo Office Combined software as well as AutoCAD for drawing conclusions regarding the manner in which the detail points could be imported.

Thus, the field data gathering with GPS, RTK were transferred into the computer by using the Notepad, Excel, Word, AutoCAD 2012 specific software.

Following the graphic data processing the necessary plans for the work were drawn, the framing plan and the verification of the framing (fig.5 and fig.6) at 1:2000 scale for urban areas and 1:25000 scale for the areas from outside the village.
Maps and topographical plans, help to a better identification of the area, and based on the topographical measurements taken, the whole plans gathering all the elements could be achieved, with rigorous verification and overexposing the contour on the orthophotoplan (fig.7).

Using the LeicaGeo Office Combined, the field data containing the spatial coordinates $\mathrm{X}, \mathrm{Y}$ and $\mathrm{Z}$, were achieved, later being transposed in plan (fig. 8).

Based on this data, the stake out of the contour lines could be achieved by using the integrated commands of the AutoCAD TopoLT, obtaining the level curves with an equidistance of 2 m. (fig.9)

After creating the level curves the TIN model was achieved by using the TopoLT software as follows: from the TopoLT menu we have selected the command Model 3D - Create Model 3D that results according the figure (fig.10)

After creating the TIN model we create the 3D model of the terrain according to the following figure (Fig. 11)

Later, using the Global Mapper software, lots of topographical elements were determined, such as terrain topographical profiles on specific directions named in the project, where the terrain topography is heavy (fig.12)

\section{CONCLUSION}

The analysis and data achieved by these thematic maps could be a starting point for a collection of topographical analysis that could be used to create the basis of future works and data processing in topographical purposes, along with 


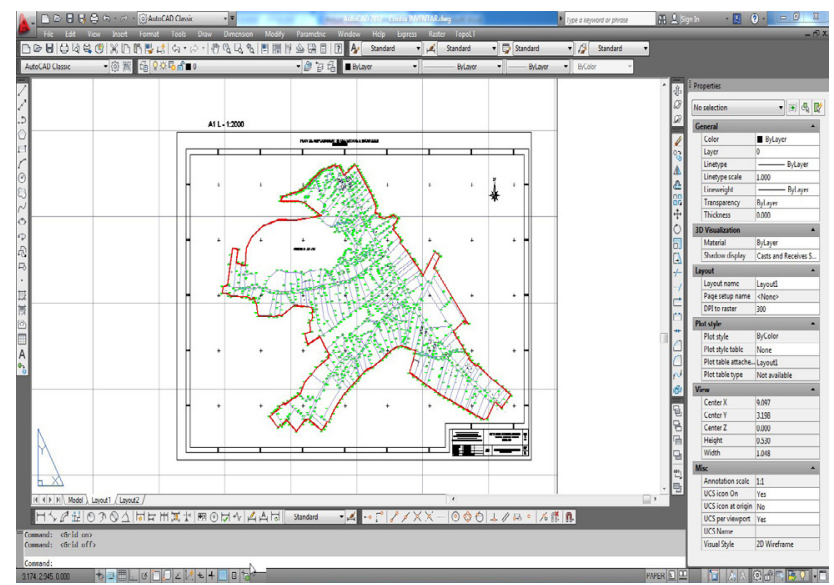

Fig.8. Situation plan containing the terrain contour points coordinates and points heights

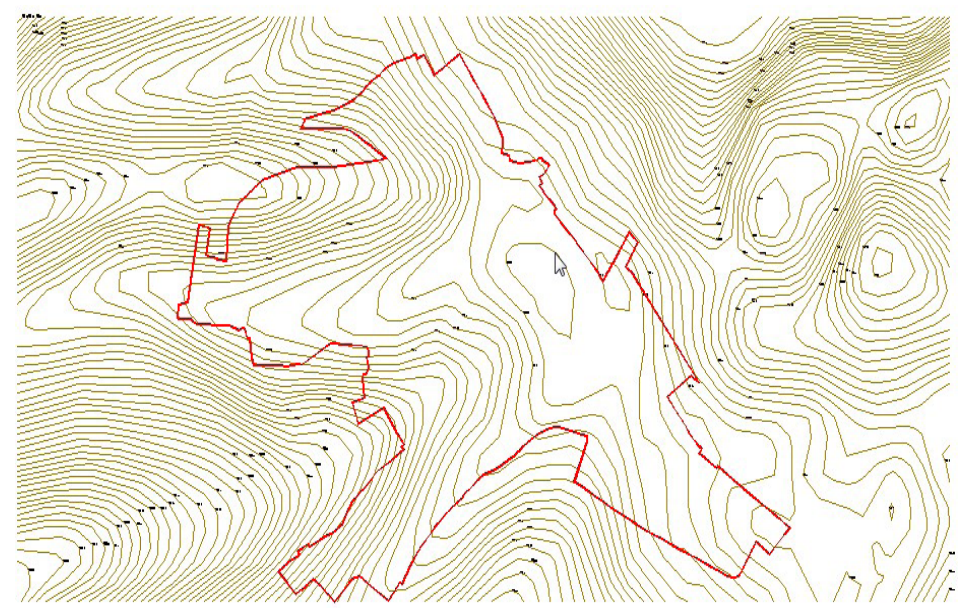

Fig.9. The situation plan containing the level curves at $2 \mathrm{~m}$ equidistance

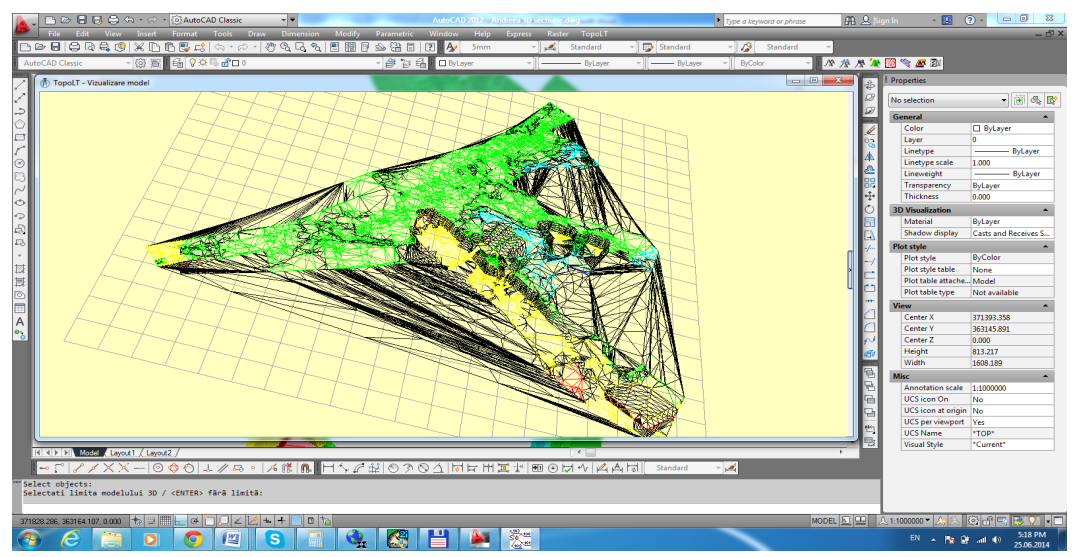

Fig.10. The TIN model of the terrain

the topo-geodetical details determined on field and later processed by specific software such as AutoCAD, TopoLT and Global Mapper.
The GPS technology, allowed us to collect topo-geodetical data on large surface, with higher accuracy in a relatively short period of time, by using small human and material resources. 


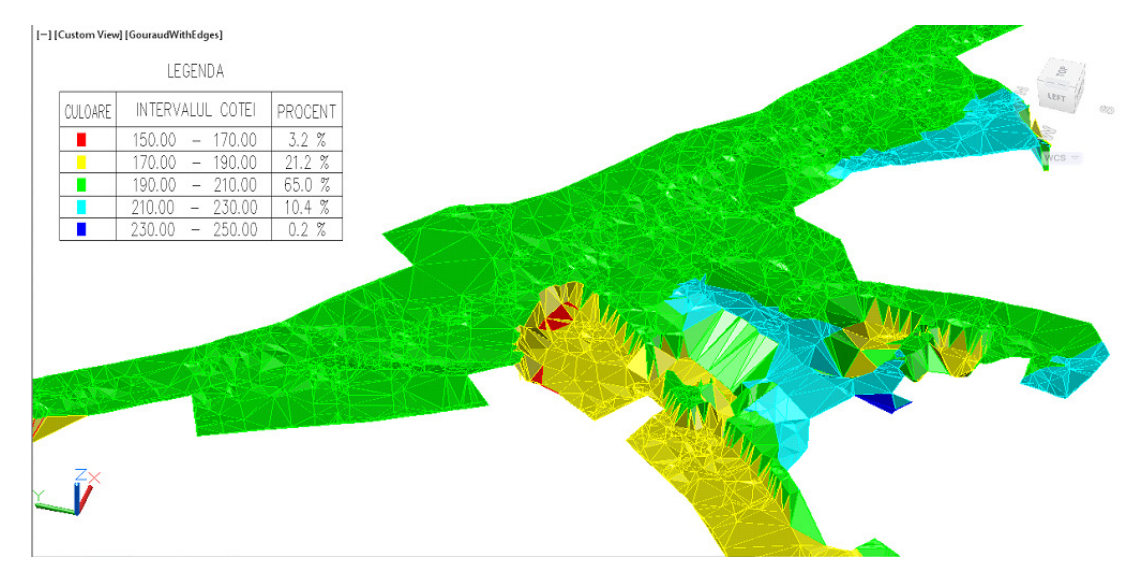

Fig.11. 3D visualization for the studied area create using the AutoCAD software
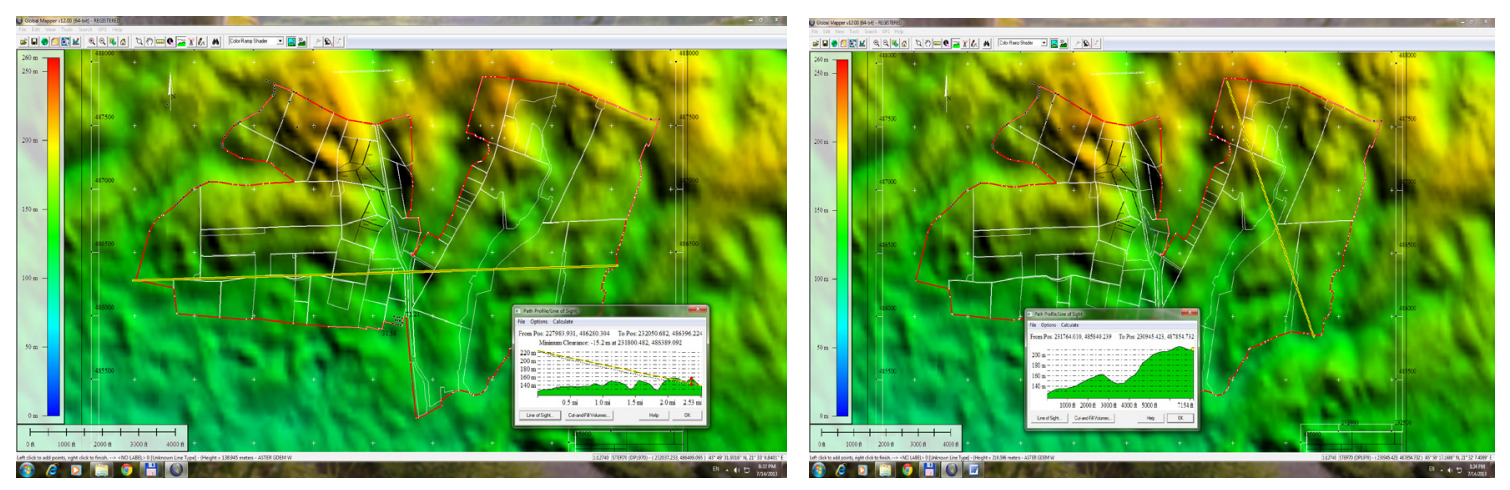

Fig.12. Longitudinal profile of the terrain along the east-west axes and north-south axes

Achieving digital plans by using AutoCAD software denote that this can be made with higher accuracy and maximum precision allowing different analysis of the terrain, including the construction of the contour lines in 2D format and 3D format by using TIN analysis.

\section{REFERENCES}

1. Bârliba L., Stoian I., (2009). Elemente de Fotogrametrie, Editura Eurobit, Timişoara.

2. Herbei M.,Nemes I., (2012). Using GIS analysis in transportation network, 12th International Multidisciplinary Scientific Geoconference, SGEM 2012, Vol. II, ISSN: 1314-2704, Pg. 1193-1200.

3. Popescu G., (2009). Sisteme interactive de modelare a informatei fotogrametrice, Editura Matrix Rom, Bucharest. 